\title{
Satellite Monitoring of Land and Vegetation around Salalah City, Oman
}

\author{
ELnazir Ramadan* \\ Department of Geography \\ College of Arts and Social Sciences \\ Sultan Qaboos University \\ Oman \\ *Corresponding author
}

\author{
Abdelrahim Salih \\ Remote Sensing Authority (RSA) \\ Sudan
}

\begin{abstract}
The present study illustrates a method for monitoring the urban vegetation around Salalah city, in Dohfar region, Southern of Oman. Monitoring spatiotemporal changes in urban areas has become increasingly important as the number and proportion of urban residents continues to increase. The synoptic view of urban land cover provided by satellite and airborne sensors is an important complement to in situ measurements of physical, environmental and socioeconomic variables in urban settings. The results obtained have revealed a notable change in the vegetation cover in and around the City premises. In this study, we discussed methodology for measurement of urban vegetation and vegetation distributions based on band ratioing in Salalah city using Land sat TM imageries. A systematic analysis of the spatiotemporal dynamics of vegetation in urban areas is required to ensure a healthy sustainable environment.
\end{abstract}

Keywords-remote sensing; band ratioing; urban vegetation; urban sustainability; salahah

\section{INTRODUCTION}

Global urbanization is one of the primary forms of environmental change directly impacting the human population. Although cities occupy a small percentage of the Earth's land area, the physical conditions of the urban environment exert a direct influence on almost half of the world's population [1]. In order to understand the physical dynamics of the urban environment, it will be necessary to quantify changes in certain key environmental parameters. Many of the important environmental parameters in urban areas are best measured by remote sensing. Optical remote sensing measures is a critical environmental parameter because it modulates energy fluxes and can be influenced by choices of building materials and land covers. Temporal variations in the albedo of the urban mosaic exert a strong influence on the energy flux through urban environments. One of the primary determinants of the albedo and surface temperatures in urban and suburban environments is the spatial and temporal distribution of vegetation.

Vegetation is one of the most sensitive indicators for environmental and global change. The behavior of vegetation change reveals the interconnected nature of climate on Earth. Aside from the expected seasonal variations, it reveals how human activities, such as deforestation and urbanization, are having a profound effect on ecosystem characteristics. The importance of vegetation change detection was made very clear, as the effects of rain forest clear-cutting were even visible from the vantage point of space. The response of vegetation to natural and human disturbances can be subtle or drastic, occurring seasonally or almost over night. The global changes observed as a result of these vegetation changes show us how delicate this world is [11]. In a view to understand both natural and socio-economic influences on vegetation cover, the present investigation comes to deal with vegetation distribution and its sequences in the urban fringe area of Salalah city.

\section{THE STUDY AREA}

The study area is part of Dhofar Governorate which is the largest region in Oman covering almost $100,000 \mathrm{~km} 2$ and having a population of 249401 according to the 2010 census. Dhofar Governorate is located in the southern part of the Sultanate of Oman bordered by the Republic of Yemen from the south, the Kingdom of Saudi Arabia from the west and the Arabian Sea from the east. It is divided into 10 zones known locally the Willayats (states). The largest town in Dhofar is Salalah. In the past, Dhofar was the main source of frankincense in the East, but now mostly used locally. Dhofar is divided into three geographic regions as shown in Figure 1: (i) the coastal plain region, (ii) the mountainous region and (iii) the desert region. The total natural pasture in Oman is approximately 26,067 hectares according to Oman Pasture Database Project which was conducted by Ministry of Agriculture in 2008. $23.8 \%$ of these areas are available in Dhofar Governorate. Natural pasture in Dhofar consists of natural grass, which mainly grows in the summer season and natural trees.

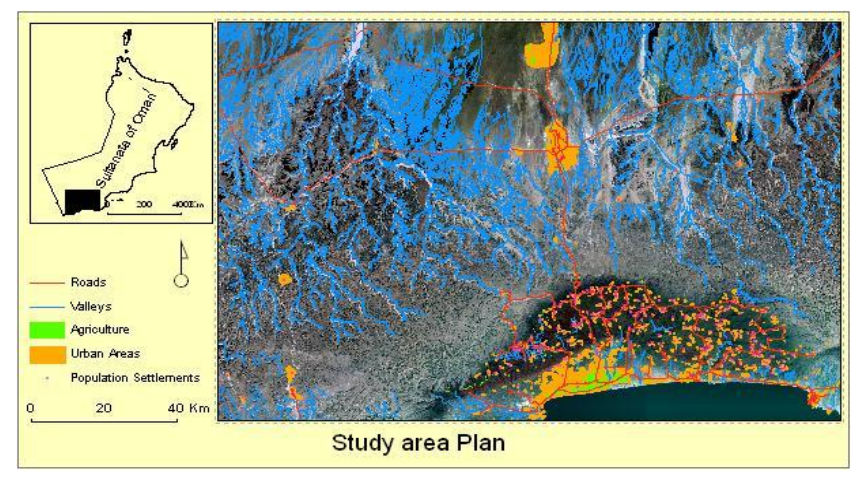

FIGURE I. STUDY AREA

III. MATERIALS AND METHODS 


\section{A. Materials}

Remote Sensing has become an inevitable tool for environmental monitoring at local, regional and global scales from the last tree decades. It has become an integral part of information technology that provides solutions to facilitate sustainable development of both natural resources and conservation of the environment. For the present Study the following imageries has been used:

(1) 1995- land sat TM image data

(2) 2010- land sat TM image data

\section{B. Methodology}

In order to detect the changes between the two images an arithmetic operations is applied to registered bands of imagery acquired on multiple dates. Hence a methodological approach based on image arithmetic (band differencing or band rationing) was followed as suggested by Jensen et al., [6]. Band differencing and rationing are usually performed with a help of a single band imagery of each dates. Image differencing involves subtracting the imagery of one date from another and the subtraction results an out put image with both "positive" and "negative" values in the areas of radiance change and zero values in the areas of no change [10].

During present study band differencing was performed using band 3 and 4 by calculating the NDVI for each image and subtracted them.(Fig 1) Typically, TM Bands 4, 3, and 2 can be combined to make false-color composite images where band 4 represents red, band 3 , green, and band 2, blue. This band combination makes vegetation appear as shades of red, brighter reds indicating more vigorously growing vegetation. Soils with no or sparse vegetation will range from white (sands) to greens or browns depending on moisture and organic matter content. Water bodies will appear blue. Deep, clear water will be dark blue to black in color, while sediment-laden or shallow waters will appear lighter in color. Urban areas will appear blue-gray in color. Clouds and snow will be bright white. They are usually distinguishable from each other by the shadows associated with the clouds.

Note that after basic processing, imagery from nonradiometric instruments may appear as photographs. With certain visual imagery (such Landsat) it is even possible to display images in more-or-less their natural color. In practice, images for display are generally manipulated to appear visually pleasing and to show interesting detail, and appear in "false color". Visible and Infrared bands may be freely mixed in false color images [2,3].

\section{RESULTS AND DISCUSSION}

\section{A. Band Differentiation between 1995 and 2010}

1) Selection of bands: Landsat Thematic Mapper (TM) provides improved spatial resolution, improved geometric fidelity, greater radiometric detail and more detailed spectral information in more precisely defined spectral regions. Characteristics of the different spectral bands and responses of each band to various surface materials have been analyzed.
Band $1(0.45-0.52 \mathrm{~m})$ : provides increased penetration of water bodies and also capable of differentiating soil and rock surfaces from vegetation and for detecting cultural features. Band $2(0.52-0.60 \mathrm{~m})$ : it is sensitive to water turbidity differences; because it $3(0.63-0.69 \mathrm{~m})$ : senses in a strong chlorophyll absorption region and strong reflectance region for most soils. Band $4(0.76-0.90 \mathrm{~m})$ : operates in the best spectral region to distinguish vegetation varieties and conditions. Because water is a strong absorber of near IR, this band has delineated water bodies. In this band croplands and grasslands have showed higher reflectance (brighter tone), it has separated vegetation (forest, croplands with standing crops) from soil. This band has highlighted barren lands, urban areas, street pattern in the urban area In this band barren lands urban areas and roads and highways have appeared as brighter (lighter) tone, but forest, vegetation, bare croplands, croplands with standing crops have a darker tone. This band has also separated croplands from bare croplands. Since standing crops (vegetation) has higher reflectance in the near IR region, they have appeared as brighter tone and due to presence of moisture content in the bare croplands, they have appeared as darker tone. In the band 4 barren lands, urban areas and highways have not been highlighted and they appeared as dark tone. Band 5 has separated forestlands, croplands, and water body distinctly. Forests have appeared as comparatively darker tone than the croplands (light gray). Band 5 has separated water body (dark tone) from barren lands, croplands, grassland (lighter tone). Since urban area and croplands have responded almost in the same spectral reflectance band 5 could not be able to separate these areas. $[8,9]$.

In the resultant image it has been noticed that all areas that witnessed change were shown in gray shade where as those of no or little change appeared in black The analysis of the image value would show the difference between vegetative and nonvegetative areas on both images, which believed to be associated with urbanization.

The study investigates changes that occurred between the two images dates. Changes in the landscape are not exclusive to that period, however; in fact, the present view of Salalah area land cover is already becoming outdated in some regions as natural and human forces continue to transform the landscape. For example, a comparison of 1995 and 2010 satellite images from the Landsat TM shows that significant changes in some areas selected for examination are taking place. Their characteristic spectral/temporal signatures may often distinguish Land cover and vegetation types from each other types. Many studies have proposed change detection techniques for monitoring urban growth based on changes in Normalized Difference Vegetation Index (NDVI) [9]. Defined as normalized difference between near-infrared and visible reflectance, NDVI can be directly related to the amount of photosynthetic (green) biomass within a pixel. Since urbanization in non-arid regions replaces vegetation (high NDVI) with building materials (low NDVI), sudden decreased in NDVI clearly indicates the urban development. Howarth and Boassan [5] have found that this was true with changes in vegetation indices strongly correlated with urban growth. 


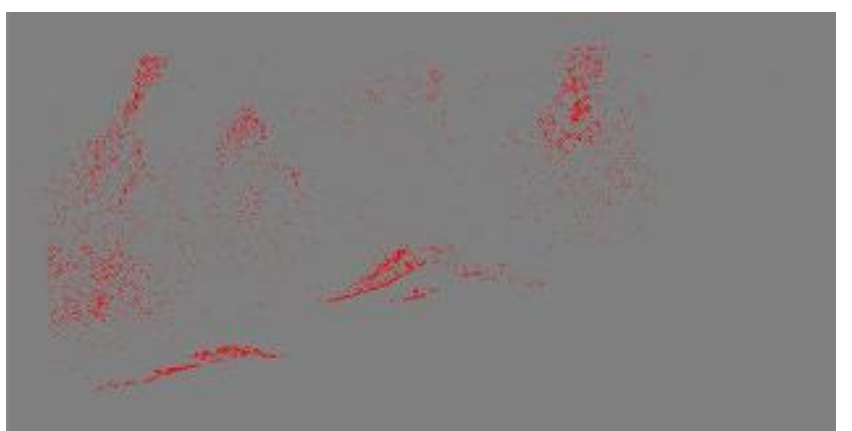

FIGURE II. NDVI RESULTS

\section{CONCLUSION}

In conclusion, the present investigation provides a simple approach to measure vegetation abundance and distribution in the Salalah area. The city is a fast growing one. The economic growth through various reforms pertaining with urban and tourism improvements brings some changes in the natural environmental setting with both advantages and disadvanges on the time scale series. The present investigation and findings provide an efficient means for systematic, quantitative analyses of a major determinant of urban environmental conditions. Although band ratioing is relatively rapid means of identifying changes in LCLU classes, but it is not efficient, several possible sources of error exist in using this technique, but they did not appear to cause serious problems in the Landsat TM scene tested. Studies in other urban areas will be necessary to assess the general applicability of this method. The role of urban vegetation distribution in the modulation of mass and energy flux through the urban system, as well as its impact on human health and environmental conditions, warrants further investigation into vegetation monitoring and its applications to urban systems. If the general applicability of the method can be established, a systematic comparative analysis of the world's major evolving urban centers could be undertaken at relatively modest expense. Such a study could yield substantial returns on the research front of comparative analyses of the role of vegetation distribution on urban environmental conditions the fact that would result in significant improvements in health, energy efficiency and quality of life for vast numbers of people in rapidly expanding urban areas.

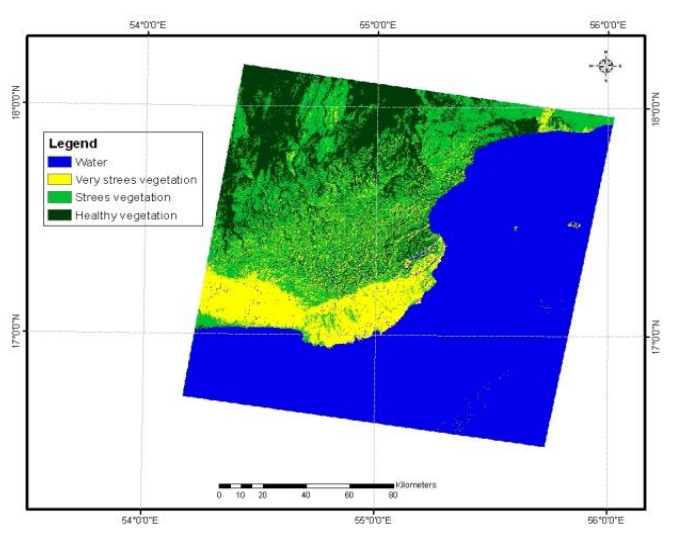

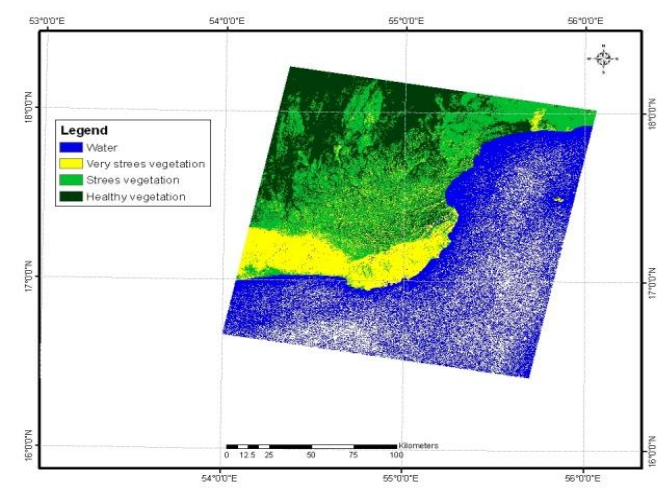

FIGURE III. NDVI IMAGE 2010-1995

\section{REFERENCE}

[1] Berry, B. L., Urbanization. in The Earth as Transformed by Human Action, edited by B.L. Turner II, W.C. Clark, R.W. Kates, J.F. Richards, J.T. Matthews and W.B. Meyer, 103-119, Cambridge University Press, Cambridge, 1990.

[2] Boardman, J. W., Inversion of imaging spectrometry data using singular value decomposition, IGARSS'89 12th Canadian Symposium on Remote Sensing, 2069-2072, 1989. Use of thermal infrared temperature and NDVI measurements to infer surface soil water content and fractional vegetation cover, Remote Sensing Reviews, 9, 161-173, 1994.

[3] Clark, R. N., and T. L. Roush, Reflectance Spectroscopy: Quantitative analysis techniques for remote sensing applications, Journal of Geophysical Research, v.89, B7, 6329- 6340, 1984.

[4] Forster, B. C., An examination of some problems and solutions in monitoring urban areas from satellite platforms, International Journal of Remote Sensing, 6, 1, 139-151, 1985. Fu, C. B., J.-W. Kim, and Z. C. Zhou, Preliminary assessment of impacts of global change on Asia. in Asian Change in the Context of Global Climate Change, edited by J.N. Galloway and J.M. Melillo, Cambridge 1998.

[5] Howarth, P.Jand Boasson, E., 1983, Landsat digital enhancement for change detection in urban environments. Remote Sensing of the Environment, 13, 149-160

[6] Jensen, J.R. 1996. Introductory Digital Image Processing: A Remote Sensing Perspective. Second edition. Prentice Hall, NJ. 316p.

[7] Lillesand, T.M., and R.W. Kiefer. 1979. Remote Sensing and Image Interpretation. John Wiley and Sons. NY.

[8] Musick, B., and Pelletier, R.E. 1986. Response of some Thematic Mapper Band Ratios to Variation in Soil Water Content. Photogrammetric Engineering and Remote Sensing. 52(10): 1661-1668

[9] Satterwhite, M.B. 1984. Discriminating Vegetation and Soils Using Landsat MSS and Thematic Mapper Bands and Band Ratios. Proceedings of American Society of Photogrammetry. 2: 479-485.

[10] Singh, A. 1989. Digital Change Detection Techniques Using Remotely Sensed Data. International Journal of Remote Sensing. 10(6): 989-1003.

[11] Todd. W.J. 1977. Urban and Regional Land use Change Detected by Using Landsat Data. Journal of research By the US Geological Survey. 5:527-534. 